\title{
Concepções em mudança do pensamento histórico no ensino da história: um estudo de caso australiano
}

\begin{abstract}
Resumo
Muitos países vivenciaram conflitos em torno do conteúdo do seu currículo de história e tiveram debates sobre a importância relativa de habilidades (pensamento histórico) versus conteúdo (conhecimento histórico). A Austrália não é uma exceção. Este artigo busca contribuir para as discussões sobre a importância do pensamento histórico no ensino da História explorando as concepções em mudança de pensamento histórico nos currículos de história de New South Wales (NSW) (o mais populoso estado da Austrália, que evoluiu de uma antiga colônia britânica e tem uma ininterrupta tradição de ensino de história no ensino médio, e um curso adicional ao ensino obrigatório, que é único no país). Recentemente, a história se tornou um tema obrigatório em todas as escolas australianas, desde o primeiro fundamental até o último ano da escola obrigatória (F-10), pela primeira vez desde a federalização dos estados australianos (1901), quando se determinava constitucionalmente que o currículo era uma responsabilidade do Estado. Este artigo mapeia as formas cambiantes e a importância relativa do pensamento histórico como um resultado explícito do ensino de história nos currículos de história de NSW, desde o seu surgimento no currículo de história eletivo da década de 1970 até a explicitação nas ementas de NSW para o Currículo "nacional" obrigatório australiano. Ele também explora a natureza e o significado do curso adicional "sênior" de história posterior à escola obrigatória de NSW, uma opção para os alunos de história no ano final não obrigatório de escolarização. Este curso adicional incorpora em grande medida o estudo da historiografia, exigindo dos alunos que apliquem suas intuições meta-históricas numa investigação historiográfica original, ancorando teoria histórica complexa numa experiência de ser historiador. Defendemos que esta atitude de incorporar a historiografia no currículo expande a noção do que constitui o pensamento histórico no ensino de história. Assim, concluímos com a reflexão sobre o que esses diferentes modos de conceituar o pensamento histórico significam para a função social e educacional da história, e quais implicações eles sugerem para o ensino da história.
\end{abstract}

Palavras-chave: Ensino da História; Pensamento Histórico; Austrália.

\section{Robert J. Parkes}

Professor de Pedagogia na Universidade de Newcastle e diretor da Rede de Pesquisa em Ensino de História HERMES. Ele ensina na área de Educação Social, de Mídia e de

História. Seus interesses de pesquisa incluem Ensino de História, Alfabetização

Meta-Histórica, Teorias de Currículos, Políticas e Histórias.

Universidade de Newcastle. robert.parkes@newcastle.edu.au

\section{Debra Donnelly}

Professora e coordenadora do curso de Pedagogia da Universidade de Newcastle, NSW, e atua tanto na graduação quanto na pós-graduação. Seus interesses de pesquisa

se concentram no papel do visual e das mídias no desenvolvimento da consciência histórica na era do acesso cada vez maior em função das novas tecnologias. Procurase investigar e esclarecer a relação entre as molduras conceituais que tem o professor em relação ao entendimento histórico, ao conhecimento problematizado e à representação e memória e prática pedagógica histórica.

Universidade de Newcastle.

debra.donnelly@newcastle.edu.au

$$
\text { Tradução }
$$

\section{Fabrício Coelho}

Mestre em Estudos da Tradução pela Universidade Federal de Santa Catarina fabricioconiglio@gmail.com

\section{To cite this article:}

PARKER, Robert J.; DONNELLY, Debra. Concepções em mudança do pensamento histórico no ensino da história: um estudo de caso australiano. Revista Tempo e Argumento, Florianópolis, v. 6, n.11, p. 137-161, jan./abr. 2014. Título original: Changing conceptions of historical thinking in History education: an Australian case study. Traduzido por Fabricio Coelho.

DOI: 10.5965/2175180306112014137

http://dx.doi.org/10.5965/2175180306112014137 


\begin{abstract}
Many nations have experienced conflict over the content of their History curriculum, and debates over the relative importance of skills (historical thinking) versus content (historical knowledge). Australia is no exception. This paper seeks to contribute to discussions over the importance of historical thinking in History education by exploring the changing conceptions of historical thinking in the History curricula of New South Wales (NSW) (Australia's most populous state; which evolved from the earliest British colony; has an uninterrupted tradition of History teaching in high schools; and a rather unique post-compulsory extension course). Recently, History has become a mandatory subject in all Australian schools from the foundation year through to the last year of compulsory schooling [F-10], for the first time since the federation of the Australian states (1901), when curriculum was constitutionally determined to be a State responsibility. This paper charts the changing forms and relative importance of historical thinking as an explicit outcome of History education in NSW History curricula, from its emergence in the 1970 s elective History curriculum to current explication in the NSW syllabi for the mandatory Australian 'national' Curriculum. It also explores the nature and significance of the post-compulsory 'senior' History extension course in NSW, an option for History students in the final non-compulsory year of schooling. This extension course boldly incorporates the study of historiography, requiring students to apply their meta-historical insights in an original historiographic investigation, anchoring complex historical theory in an experience of being an historian. We argue that the move to incorporate historiography into the curriculum expands the notion of what constitutes historical thinking in History education. Thus, we conclude by reflecting on what these different ways of conceptualising historical thinking mean for the social and educational function of history, and what implications they suggest for History education.
\end{abstract}

Keywords: History Teaching; Historical Thinking;

Australian. 


\section{Introdução}

Muitas nações colonizadoras experimentaram, após o período colonial e seus conflitos, "guerras de história" acirradas em torno das representações do seu passado nacional, levando a um interesse político cada vez maior pelo ensino de história (TAYLOR \& GUYVER, 2011). Na Austrália, uma década de conflito cultural sobre a narrativa nacional (ver CLARK, 2004) levou a um apoio político bipartidário a um currículo de história “nacional” (um desenvolvimento significativo na Federada Commonwealth da Austrália, uma vez que o currículo é constitucionalmente uma responsabilidade do Estado, que levou a um fracasso das precedentes tentativas de formar um currículo nacional). Com o advento deste novo currículo "nacional” australiano (2013), a história se tornou uma área obrigatória de estudo em todos os estados australianos, do primeiro ao último ano de escolaridade obrigatória.

Como é lugar-comum na história curricular de muitas nações, o ensino da história frequentemente também foi um campo de batalha de debates sobre a importância relativa de habilidades (pensamento histórico) versus conteúdo (conhecimento histórico) (para um instigante tratamento do problema no Reino Unido, ver COUNSELL, 2000). A Austrália não é uma exceção. Este artigo procura contribuir para a discussão sobre a importância do pensamento histórico no ensino de história explorando as concepções cambiantes do pensamento histórico nos currículos de história de New South Wales (o mais populoso estado australiano, que se desenvolveu de uma antiga colônia britânica). New South Wales (NSW) foi escolhido para um estudo de caso por um número de razões, não menos por sua longa e ininterrupta tradição no ensino de história no ensino médio, e, o que é mais importante, seu curso adicional de história posterior à escola obrigatória que é relativamente único.

$\mathrm{O}$ artigo tem três objetivos específicos. Primeiramente, ele documenta as formas cambiantes e a relativa importância do pensamento histórico como um resultado explícito do ensino de história nos currículos de história de NSW, desde o seu surgimento nos anos 1970, e melhoramento nos currículos de história eletivos dos anos 1980 (fortemente influenciados pelo trabalho do Conselho Britânicos de Escolas) até a atual 
explicitação na ementa de NSW para o currículo "nacional” australiano. Em segundo lugar, ele explora o surgimento e a significância do curso adicional de história "sênior" posterior ao ensino obrigatório em NSW, uma opção para alunos de história (aqueles que estudam história moderna ou antiga) no ano final de escolaridade não obrigatória. Este curso adicional incorporou em grande medida o estudo da historiografia, aceitando claramente que os alunos veteranos de história tem a capacidade de entendimento metahistórico. O curso adicional pede que os alunos apliquem suas intuições numa investigação historiográfica original, ancorando teoria meta-histórica complexa numa experiência de ser historiador. Defendemos que esta atitude de incorporar a historiografia no currículo expande a noção do que constitui o pensamento histórico no ensino de história, e assim nosso objetivo final é refletir sobre o que esses diferentes modos de conceituar o pensamento histórico significam para a função social e educacional da história; e quais são as implicações de tais conceituações para o ensino de história.

\section{Pensamento histórico, entendimento histórico e alfabetização histórica}

Debates recentes sobre o ensino de história nas escolas da Austrália refletiram controvérsias internacionais que veem a falta observável de conhecimento histórico e engajamento por parte do jovens como uma incompetência tanto do currículo quanto da prática docente. Contudo, mais do que uma resposta a uma falha educacional, estes debates são, ao que tudo indica, um sintoma de uma mudança de paradigma no pensamento educacional, e no ensino de história em particular, em razão de um atraso no entendimento, por parte da ampla comunidade, de modelos construtivistas do aprendizado dos alunos. Sob a influência de teorias de desenvolvimento educacional, cultural e social que rejeitam o aprendizado como uma recepção do conhecimento, "o pensamento histórico" surgiu como um termo usado pelos professores de história para rejeitar o ensino de história como uma simples função de memorização e repetição. $O$ velho acordo de uma década e meia na literatura educacional afirma que o pensamento histórico exige o desenvolvimento de habilidades e conceitos heurísticos e 
uma questão à qual voltaremos ainda neste artigo. Contudo, qualquer tentativa de providenciar uma definição de pensamento histórico apresenta uma dificuldade imediata, porque não há um significado "padrão" ou certo do termo.

Os pesquisadores do campo do ensino de história usam vários termos que estão, ao que tudo indica, tentando descrever o mesmo (ou um estreitamente relacionado) conjunto de conceitos e habilidades.

“O pensamento histórico" é um termo popular entre pesquisadores norteamericanos, tais como Sam Wineburg (2001), para quem ele forma uma expressão fundmental em seu livro Historical Thinking and Other Unnatural Acts: Charting the Future of Teaching the Past; e Peter Seixas (2006), que desenvolveu um modelo elaborado para "o pensamento histórico" em Benchmarks of Historical Thinking: A Framework for Assessment in Canada, que representou uma mudança desde os seus primeiros escritos, em que "o entendimento histórico" foi usado para ideias semelhantes (veja, por exemplo, Seixas, 1993a; 1993b). Wilson e Wineburg (1998) sugerem quatro indicadores de "profundidade" na história: (1) o entendimento de múltiplas facetas de um conceito ou evento histórico; (2) o conhecimento de detalhes destas; (3) o entendimento da natureza incompleta do conhecimento histórico; e (4) ser capaz de integrar esses entendimentos em conexões temáticas e causais mais amplas. Wineburg (2001) também notou que os historiadores, no seu estudo, exploravam as entrelinhas de um documento considerandoo tanto como um artefato retórico quanto como um instrumento, usando estratégias de fontes, de corroboração e contextualização. Como uma alternativa à noção de "pensamento histórico", especialistas em educação usam os termos "alfabetização histórica" (TAYLOR \& YOUNG, 2003; LEE, 2005; VIRTA, 2007) e "raciocínio histórico" (LEINHARDT ET AL., 1994; VAN BOXTEL \& VAN DRIE, 2004). Cada um desses termos enfatiza a importância dada ao ato de esquadrinhar sob a superfície narrativa (ou a interpretação) que é encontrada, e envolve o que Lee e Ashby (2000) chamam de conceitos ou ideias de segunda ordem. De acordo com Lee e Ashby (2000, p. 199), "são 
coexistente com um "entendimento histórico", e que compreende tanto atos de “raciocínio histórico”, quanto o engajamento na "alfabetização histórica”.

Nas últimas décadas, os educadores e pesquisadores da área de história envidaram esforços para esclarecer os componentes do pensamento histórico. Grande parte da pesquisa inicial foi conduzida no Reino Unido em associação com o Projeto Schools History nos anos 1980. A avaliação de Shemilt (1980) desse projeto é um trabalho seminal sobre o pensamento histórico e o ensino de história. Ele inicia uma abordagem que enfatizava a evidência como blocos de construção da explicação e da narrativa histórica, e encorajava uma investigação que fazia o estudante o centro do processo investigativo. Grande parte da pesquisa que veio depois pode traçar a sua genealogia à iniciativa do projeto Schools History, tal como o trabalho do influente pesquisador canadense Peter Seixas.

Seixas (2006) define o pensamento histórico como as experiências coletivas organizadoras do passado, tais que formam um modo significativo de pensar o presente. Ele sugere que há três elementos do entendimento histórico dos estudantes. O primeiro é a habilidade de dar importância à informação histórica e estabelecer critérios pelos quais se pode julgar a significância de várias narrativas do passado, frequentemente competindo entre si. O segundo elemento é a abordagem epistemológica pela qual as interpretações são revistas através da inclusão de nova evidência ou opinião. Este elemento envolve as habilidades de análise de fonte, a integração de opinião secundária e a aplicação de molduras pelas quais se pode julgar a confiabilidade da cacofonia de vozes que falam do passado e do presente. O terceiro elemento incorpora ação, empatia e julgamento moral. A ação histórica é a noção de que escolhas individuais e as ações de indivíduos ou grupos têm impacto na narrativa histórica e têm consequências intencionais e não-intencionais. A empatia é a habilidade de ver além do seu próprio tempo, da sua própria cultura do seu sistema de valores para observar a ação do passado. É a habilidade de entendimento que permite ao passado uma entrada limitada no mundo do presente 
histórica é um processo complexo que envolve a análise e a interrogação de fontes evidenciais individuais; a sintetização do seu significado e inter-relações; enquanto simultaneamente constrói um novo conhecimento e integra este novo conhecimento em narrativas existentes. Investigar historicamente é pôr em ação atividades mentais reflexivas e dotadas de propósito, as quais têm como foco a exploração estratégica de múltiplas perspectivas através da avaliação da confiabilidade e da perspectiva da geração de interpretações e entendimentos (BARTON, 2004; WINEBURG, 2001). Em conjunto, essas atividades intelectuais complexas constituem a habilidade do pensamento histórico. Após reconstituir o significado da atividade complexa do pensamento histórica, queremos agora voltar-nos ao currículo de NSW, e ao modo pelo qual a ideia de pensamento histórico se desenvolveu neste sistema escolar australiano ao longo do tempo.

\section{O movimento em direção do pensamento histórico nos anos 1970}

Um currículo introdutório de “Estudos Sociais” numa Classe I (Ano 7), seguido pela possibilidade de um estudo optativo de história nas Classes II, III e IV (Ano 8-10) era o padrão de estudo nas escolas de NSW desde a adoção do "Wyndham Scheme" - um sistema de ensino secundário compreensivo implementado pela primeira vez em 1962 (JOHNSTON, 1982). As reformas de Wyndham tinham o objetivo de levantar os padrões acadêmicos em parte pela introdução de um exame externo no fim da lasse IV (um sistema que continuou até há pouco tempo).

Em toda a década de 1960, o ensino de história era guiado por uma "ementa prescritiva e cronológica, programada em seções quinzenais de conteúdo" (JOHNSTON, 1982) que permaneceu relativamente sem modificação até 1972 (CLARK, 2003). De acordo com Anna Clark (2003, p. 173), as “abordagens críticas à história australiana” que estavam vindo da academia durante os anos 1960 e 1970, e que estavam começando a questionar 
prescritiva" voltada a uma pesquisa discente "que maximizava a liberdade dos professores e alunos na escolha do conteúdo e da metodologia adequados ao seu interesse, aos níveis de habilidade e às circunstâncias escolares" (JOHNSTON, 1982). Contudo, vale a pena notar que a história da Austrália permaneceu uma área de estudo para os anos facultativos.

Na ementa de 1971, houve uma mudança significativa para habilidades de pensamento histórico com uma ênfase no ensino de "avaliação crítica" e “interpretação", e em dar aos alunos "uma consciência de alguns dos problemas e técnicas do historiador" (Secondary Schools Board, 1971, p. 3). Pela primeira vez, os alunos foram posicionados como participantes ativos no ato de fazer história, desenvolvendo habilidades tais como "usar e avaliar dados" e formular hipóteses e argumentos (Secondary Schools Board, 1971, p. 14). Esta ementa introduziu "Atitudes e Valores", objetivos que encorajavam a tomada de perspectiva e a empatia, "um entendimento de ideias, aspirações e diferenças culturais de pessoas em outros tempos e lugares" (Secondary Schools Board, 1971, p. 3). Incluiu os conceitos de "mudança e continuidade" e enfatizou a significância da história para o indivíduo quando afirmava que "o aluno deveria desenvolver o sentido da história como um processo contínuo do qual ele participa" (Secondary Schools Board, 1971, p. 4). Um artigo que discutia o assunto, lançado em 1975, resumiu o humor do tempo, afirmando que "a história é um estudo natural para os jovens, eles são curiosos sobre o passado... Negar a história aos jovens é privá-los do seu significado cultural, torná-los amnésicos sociais" (como citado em JOHNSTON, 1982, p. 72). Em NSW, a ementa de 1972 reavivou a fortuna decadente da história escolar e estabeleceu-a firmemente como uma matéria discreta, já não como parte de um amálgama de ciências sociais. Começou a mover-se para um pensamento histórico com seus conceitos de interpretação, avaliação e empatia, e evocou um forte senso de propósito para a história escolar como uma matéria que ajuda os jovens a encontrar o seu lugar no mundo. 


\section{A influência britânica nos anos 1980}

Uma nova ementa lançada em 1980 intensificou o foco no desenvolvimento do entendimento histórico dos alunos em NSW (JOHNSTON, 1982). Uma ampla gama de tópicos estava disponível para seleção. Eles incluíam o estudo do "homem primitivo" [sic] através do Renascimento, da Bretanha sob os Tudors; vários aspectos do Império Britânico e do Imperialismo Europeu em geral; e Mudanças Políticas na Europa. Houve uma mudança no nono ano para a história colonial australiana, com certa ênfase na herança local, culminando com uma visão ampla da história australiana do século XX no contexto mundial. Esta ementa foi valiosa por se afastar da concepção de história em "termos limitados dos temas" e pela mudança para "uma atenção sistemática que foi dada ao processo e às habilidade de raciocínio, assim como a valores e atitudes" (FITZGERALD, 1981, p. 73). Deu-se aos professores a liberdade de criar um ambiente em que os alunos fossem estimulados a fazer suas próprias descobertas sobre a história (Secondary Schools Board, 1980, p. 20). Esta ênfase na investigação e na interpretação de evidência para criar narrativas históricas que são "a história das pessoas" dá mostras da forte influência do projeto "History 13-16" do Conselho Escolar Britânico. Isto não é surpreendente, uma vez que a equipe do Conselho Escolar Britânico visitou a Austrália durante o período para disseminar seus achados e sua abordagem, e fez uma série de oficinas populares para professores em serviço em NSW (JOHNSTON, 1982). A ementa de 1980 está em concordância com o ponto de vista dos Projetos, segundo o qual a história "envolve a busca de evidência e pistas sobre pessoas no passado" e "envolve fazer perguntas." (Secondary Schools Board, 1980, p. 2). Uma maior ruptura com as ementas precedentes, ainda seguindo a condução britânica, foi a relevância dada ao que foi chamado de "perspectiva histórica." Esta noção abarcou o desenvolvimento nos alunos de "um senso do tempo, um senso de relações de causa e efeito, e um entendimento das interações entre passado e presente" (Secondary Schools Board, 1980, p. 10). De modo mais importante, esta noção culminou na consideração da significância histórica, "um entendimento de que a história é uma relação dinâmica de pessoas, lugares e tempos em que alguns eventos podem ser julgados como mais significantes do que outros" 
(Secondary Schools Board, 1980, p. 10). A empatia era vista como um parceiro essencial para o desenvolvimento de uma perspectiva histórica e central para o ensino e aprendizagem da história, fornecendo uma "habilidade para sentir com, e aprender das pessoas do passado ao entrar imaginativamente no seu mundo" (Secondary Schools Board, 1980, p. 11). Com a ementa de 1980, os entendimentos dos pensamentos históricos foram prescritos para o ensino, a aprendizagem e a avaliação explícitos, e os alunos eram encorajados a adotar a metodologia e a manifestar as sensibilidades do historiador, ou o que poderíamos descrever como um "olhar disciplinar" (olhar com os olhos de um historiador). Assim, os anos 1980 registraram um avanço significativo em direção de como pensaríamos sobre o pensamento histórico nas três décadas seguintes.

\section{Os radicais e reacionários anos 1990}

A década de 1990 viu o início de uma crescente burocratização do currículo, começando com o surgimento de uma autoridade curricular estatutária em NSW, o Conselho de Estudos [Board os Studies - BOS] (HARRIS, 2004). Contudo, para a maioria dos educadores, políticos e os comentaristas das mídias, o currículo de história dos anos 1990 será lembrado como um período de conflito com interpretações rivais do passado da nação (HENDERSON, 2005); e para os educadores de história atentos à mudança curricular de uma área facultativa de estudo para um componente obrigatório dos currículos para os alunos de 7 aos 10 anos de NSW. Houve um grau de hesitação mostrado pelos professores nesta atitude que tornou a história da Austrália obrigatória, dado que a maior parte dos alunos e a maioria dos próprios professores parecem - até hoje - achar a matéria da história australiana um tanto "chata" (CLARK, 2008). Contudo, mesmo que os próprios professores achassem pouco interesse na história da Austrália, isto não foi o caso para políticos e para a mídia conservadora por razões que ficarão claras abaixo.

Surgindo na sequência de mudanças significativas e de um crescente número de bolsas para a historiografia aborígene, que ganhou atenção pública no tempo do Bicentenário, e teorias feministas que estavam circulando desde os anos 60, a ementa de 1992 foi a primeira ementa de história em NSW a incorporar histórias sociais sobre e da 
que vieram à tona na academia no final dos anos 1970 e início dos anos 1980 como as histórias sociais "que enfatizavam as vidas das pessoas simples", em contraposição ao estudo das elites (MACRAILD \& TAYLOR, 2004, p. 120), legitimaram o lugar no currículo de "história a partir de baixo" de NSW (SHARPE, 1991) e apresentaram-no como uma opção que apela contra as narrativas mestras dos "homens famosos" e da "colonização pioneira". Enquanto "a perspectiva histórica" foi reconhecida como um aspecto do ensino de história nos primeiros currículos e foi sinônimo da adoção do olhar disciplinar do historiador, os anos 1990 apresentaram um noção relativamente diferente das “perspectivas" como um componente crítico do pensar histórico. O que se quis dizer com “perspectivas" nos anos 1990 já não era a adoção da posição desapaixonada do historiador, mas da posição controlada pela disciplina (como foi sugerido pela noção de “perspectiva histórica” nos anos 1980), mas um posicionamento empático de si mesmo na pele dos povos indígenas, mulheres e imigrantes, aqueles marginalizados nas grandes narrativas da nação. Os alunos recebiam a tarefa de ver a história de novos pontos de vista.

Uma mudança na linguagem que tradicionalmente descrevia a colonização britânica como "estabelecimento", no sentido de um reconhecimento sem precedentes da perspectiva aborígene sobre a colonização como "invasão", gerou muito receio na intelligentsia conservadora de NSW (MACINTYRE, 2004), de Queensland (LAND, 1994), e de Vitoria (GRIMSHAW, 1996), onde mudanças curriculares similares tinham acontecido. Descrita como "radical" por comentadores posteriores (THOMPSON, 1999; PARKES, 2007), esta ênfase nas perspectivas de grupos marginalizados historicamente dentro da sociedade pôs o ensino de história em rota de colisão com os historiadores e políticos conservadores, gerando um campo de batalha numa série de "guerras de história" acirradas e amplamente públicas (MACINTYRE \& CLARK, 2003). No cerne das "guerras de história" estava a preocupação de que a consciência histórica dos jovens da nação estava sendo cooptada pela tentativa de radicais de esquerda de pendurar uma "fita negra" ou 
De vários modos, as batalhas em torno da história que ocorreram em NSW depois do lançamento da ementa de 1992 foram emblemáticas de conflitos sobre o ensino de história nos países de língua inglesa (ALDRICH, 1991; NASH et al., 1998; PHILLIPS, 1998; G. H. RICHARDSON, 2002) e em várias sociedades que passaram por conflitos (AL-HAJ, 2005; AHONEN, 2012); e refletiram, ao que tudo indica, um fenômeno global (TAYLOR \& GUYVER, 2011). O que é percebido como estando em jogo nessas "guerras de história" é o futuro da nação (HALSE \& HARRIS, 2004), porque, como Bennet (1995, p. 162) defendeu, "a forma do futuro pensável depende de como o passado é retratado e de como suas relações com o presente são pintadas". Quando um governo federal conservador foi eleito em 1996, a retórica de Blainey de um "balanço patrimonial” e de "uma história de fita preta" entrou no léxico nacional, e NSW respondeu desenvolvendo o que pode ser descrito somente como um currículo de história reacionário, esvaziando o documento radical de 1992 em favor de currículo mais contido, conservador e guiado pelo conteúdo em 1998 (ver Board of Studies Nsw, 1998). Este currículo de 1998 altamente prescritivo mal tinha sido implementado quando o reação dos professores levou ao lançamento de uma nova ementa em 2003.

\section{Pensamento histórico no novo milênio}

Embora o novo milênio tenha começado com uma consciência pública cada vez maior das "guerras de história" (MACINTYRE \& CLARK, 2003), o currículo de história de NSW tinha resolvido a questão da importância relativa do conteúdo histórico e do pensamento histórico, dando nova ênfase ao lugar do pensamento histórico no currículo, e sacralizando-o de novos modos. Fê-lo tornando tanto o conteúdo quanto as habilidades explícitas no currículo por meio de uma série de resultados consistentes em "aprender sobre" (conhecimento histórico) e "aprender a [fazer]" (habilidades históricas). Ademais, ele exigiu o estudo - tanto como uma unidade discreta quanto integrada nas demais 

que deveriam ser integradas em cada tópico de estudo, incluindo: (1) compreensão; (2) análise e uso das fontes; (3) perspectivas e interpretações; (4) compreensão empática; (5) pesquisa; e (6) comunicação (Board of Studies Nsw, 2003, p. 22). Finalmente, ele articulou para cada tópico as habilidades históricas que deveriam ser integradas, e descreveu esta seção de cada tópico como "trabalhar historicamente". Isto foi, ao que tudo indica, a formulação mais explícita e detalhada das habilidades de pensamento histórico que foram vistas no currículo de NSW.

Quando o Primeiro Ministro conservador, John Winston Howard (2006), convocou "uma renovação desde as raízes até o ramos" da história australiana e eu um passo na direção de um currículo nacional com a sua "cúpula de história nacional” em 2006, ele não estava apenas buscando uma narrativa nacional para unificar a nação na era do terrorismo global (HOWARD, 2006), mas também lamentando o fato de que a história tinha sido relegada a um estudo facultativo nos anos posteriores à escola obrigatória em muitos estados e territórios, e submergido no que ele viu como um currículo de estudo sociais integrados “de esquerda”. A Cúpula de História Nacional devia começar a moverse na direção de um currículo de história nacional, e os artigos que examinavam o ensino e a aprendizagem da história nas escolas australianas (TAYLOR \& CLARK, 2006), e que convidavam a uma abordagem narrativa para a história australiana (MELLEUISH, 2006) foram o estímulo para o debate. Tony Taylor (2009) documentou a tentativa fracassada do governo Howard de manipular a direção do novo currículo, que recebe uma avaliação positiva em comparação com outras mudanças que ocorreram em relação ao currículo de história no Reino Unido (GUYVER, 2009), embora o retorno do partido conservador Liberal ao poder em 2013 tenha trazido consigo a iminente ameaça de uma reescrita do currículo australiano mesmo antes que estivesse totalmente implementado (CROWE, 2014).

Apesar do seu destino de logo prazo incerto, o currículo nacional de história está sendo lentamente apresentado nos estados, com a implementação para acontecer em 

integrado a outros estudos (refletindo o componente de "história investigativa" da ementa de 2013). O currículo é dividido em uma série de estudos de profundidade, que incluem história antiga, do Mediterrâneo, asiática, ocidental e islâmica, e dos mundos asiático-pacíficos, e colonial, e uma gama de tópicos da história australiana (incluindo-se o estudo obrigatório da Primeira e Segunda Guerras Mundiais; e a história aborígene a partir de 1945 como um estudo das mudanças nos "Direitos e Liberdades"). Há uma ênfase importante na Ásia na seleção de tópico, e uma notável perspectiva de história mundial (o legado do impulso da narrativa descrito acima, mas também situado na abordagem de "História Mundial" que parece estar tornando-se internacionalmente popular).

A Austrália está se esforçando na fase de implementação de um Currículo Nacional de História, que tem o objetivo de oferecer uma abordagem coletiva para diversos sistemas de educação de administração estatal. Habilidades e entendimento históricos fazem parte em grande medida da nova ementa nacional de história, e isto está embutido nos objetivos e resultados. No nível nacional, o currículo põe ênfase no "conhecimento e entendimento históricos" expressos como conceitos-chave de: evidência, continuidade e contestabilidade (traduzidos como "conceitos de história" na ementa de NSW). Ele coloca uma ênfase igual nas "habilidades históricas", descritas como: cronologia, termos e conceitos; questões e pesquisa de história; análise e uso de fontes; perspectivas e interpretações; explicação e comunicação. Interessantemente, na sua tradução para o contexto de NSW, “o entendimento empático" é acrescentado como uma habilidade adicional, não articulada como tal no quadro nacional. E o que é importante para os professores de NSW, as habilidades históricas delineadas no currículo nacional refletem algo como um "upgrade" de elementos do pensamento histórico delineado na ementa de história de 2003, ou às vezes uma inversão sutil do modo como foram expressos neste documento anterior. 
Certamente, é de algum modo a-histórico, mas lugar comum, admitir que o passado era menos “desenvolvido" que o presente. Quando olhamos para o surgimento relativamente recente da pesquisa sobre o pensamento histórico, é fácil supor que o pensamento histórico deve ter sido tardio no currículo. Contudo, nossa investigação sobre o surgimento e a evolução do pensamento histórico no currículo de história de NSW desafia esta suposição. Com efeito, examinar os documentos curriculares de 1970 até o presente mostra uma longa tradição de foco na importância do desenvolvimento de habilidades de pensamento. Contudo, o currículo obrigatório não é uma história acabada em NSW, e agora queremos mudar o foco para o curso de Extensão de história que é o único oferecido para alunos de história excelentes no último ano da escola obrigatória. Acreditamos que este currículo de "extensão" oferece uma abordagem radicalmente diferente para o pensamento histórico, que vai além do desenvolvimento de um olhar disciplinar, para a formação de entendimento meta-histórico.

\section{Pensamento histórico, historiografia e história adicional}

O curso adicional de história avançado representa o que se tornou um novo e instigante passo no currículo de história de NSW. Surgido como parte do "New Higher School Certificate" em 2000, a história adicional (como é conhecido na região) é um curso avançado de estudo para alunos talentosos ou com alto aproveitamento, contemplando História Antiga ou Moderna (no último ano da educação posterior à obrigatória). A história adicional foca no trabalho de historiadores através do tempo; o papel dos historiadores na sociedade; e os usos do passado. Este curso oferece aos estudantes a oportunidade de pesquisar um tema da sua própria escola, usando a lente do historiógrafo como um modo de entender como os historiadores constroem as representações do passado. No seu foco de "como os historiadores trabalham... a natureza da história, e como e por que as abordagens e as interpretações [históricas] mudaram no tempo" (Board of Studies Nsw, 2000, p. 6), este curso de estudos coloca uma ênfase significativa nos debates fundamentais que ocorreram sobre a natureza do conhecimento histórico, e assim introduz os alunos em várias escolas de historiografia. 

reconhece que diferentes as abordagens de fazer a história levaram às diferentes interpretações do mesmo passado. Em essência, troca-se o estudo da história pelo engajamento numa investigação meta-histórica séria e apoiada em cuidadoso escrutínio de várias tradições historiográficas dentro das quais as histórias são produzidas, disseminadas e debatidas.

O programa adicional de história induz os alunos ao que Parkes (2011) chamou de “olhar historiográfico". Este olhar envolve estender o campo perceptual do historiador de tal modo que nada lhe escape, nem mesmo ele próprio; revelando assim a especificidade histórica de todas as formas de conhecimento e prática históricas. Resulta no reconhecimento de que não somente os vestígios do passado são "históricos" num sentido convencional, mas, seguindo aqui Gadamer (1992), que nossa própria consciência como historiadores é construída dentro de horizontes e preconcepções das tradições historiográficas nas quais entramos. O olhar historiográfico leva o pensamento histórico às suas conclusões lógicas, não permitindo que nada fique fora da história. Se o estudo da historiografia torna visível a genealogia de uma dada representação histórica pelo seu revestimento com um conjunto de balizas temporais, o olhar historiográfico nos compele a reconhecer os horizontes históricos contingentes dentro dos quais toda interpretação é produzida. O estudo da história é transformado por meio deste processo, fornecendo o pano de fundo da construção retórica e da historicidade de todas as interpretações do passado. Invocar a contingência da representação histórica nos convida a apreendê-la como aberta à mudança, não sendo nunca a última palavra. A historiografia como discurso meta-teórico revela que a história é um "sistema de raciocínio" que estende o olhar do historiador a tudo, até mesmo a ele próprio. O olhar historiográfico é assim uma força interruptiva que torna as representações históricas contingentes no tempo, lugar, cultura e método.

O curso adicional de história apresenta aos alunos o que é verossimilmente uma reconceitualização da história. Sua resistência a uma aceitação sem mais do método 
com os padrões de quem, com o passado de quem?" Estas questões convidam a um engajamento com a historiografia e suas tradições que competem, cada qual com suas próprias convenções, metodologias, discursos, padrões e representações do passado. Como Yilmaz (2007) defende, para entender histórias precisamos ter um claro sentido das tradições historiográficas das quais elas surgem. Em face de relatos que competem entre si de um único evento, os alunos que aprendem dentro de uma abordagem historiográfica para o ensino de história podem receber a tarefa de explorar não somente as perspectivas alternativas, mas desenvolver um entendimento de como cada uma dessas perspectivas tem sua própria história, e é derivada da aplicação de diferentes princípios, padrões e abordagens metodológicas. Mais uma vez, como Segall (2006) claramente afirma:

Questões desse tipo ajudam a tornar visíveis e problemáticas as pressuposições de discursos, valores e metodologias que legitima e reforçam versões e visões particulares quanto ao que o passado é e o que implica saber e agir em relação a ele. (p. 139)

Ao assumir uma abordagem historiográfica para o ensino de história, duas coisas se tornam evidentes. Primeiramente, precisamos entender que as interpretações históricas são construídas dentro de tradições historiográficas particulares tais como o feminismo, o marxismo, a história social, a história intelectual, a história cultural etc.), e são então marcadas pelos vieses daquelas tradições metodológicas. Entender o quadro historiográfico dentro do qual uma narrativa histórica foi construída é o primeiro passo para entender as pressuposições carregadas de valor dos historiadores; uma disposição para formas particulares de interpretação; e uma preocupação com diferentes formas de evidência. A segunda coisa que emerge é que chegamos a entender como nossa leitura e interpretação de fontes primárias e secundárias são formatadas pelos vieses metodológicos de tradições historiográficas nas quais tenhamos sido introduzidos (PARKES, 2009). Interessantemente, Hughes-Warrington et al. (2009), em sua investigação acerca do pensamento histórico entre estudantes universitários, 
descobriram que o estudo de história no curso de bacharelado fazia pouco para mudar o entendimento dos estudantes sobre a natureza da história como uma disciplina, mas que os estudantes que tinham completado o curso adicional de história no ensino médio chegavam à universidade mais preparados para participar de discussões como seus professores e colegas sobre a natureza do conhecimento histórico. Como HughesWarrington et al. expõem, isto sugere que o curso adicional de história desenvolve a capacidade dos estudantes de participar de um discurso histórico de um modo como não acontece com outras abordagens de pensamento histórico.

\section{Conclusões}

Neste artigo investigamos o surgimento do "pensamento histórico" e seus conceitos cambiantes no currículo de história de NSW e defendemos que é possível ver um contínuo interesse em e uma evolução do pensamento histórico nos currículos a partir da década de 1970 até o presente. Ademais, poderíamos afirmar que o Currículo de História Nacional pode ser entendido em alguns respeitos como uma propagação desta evolução em toda a nação. As habilidades de pensamento histórico são vitais para a cidadania democrática; a habilidade de discutir e escutar diferentes perspectivas; considerar uma gama de opiniões e valores; e chegar a conclusões razões; e elas operam como um caminho para o desenvolvimento de uma consciência histórica sofisticada, que os bem informados podem usar como uma ferramenta para navegar no mundo social, entendendo e interpretando-o. Os professores de história são frequentemente chamados a fomentar investigações de assuntos controvertidos, examinando tópicos tais quais o racismo, a escravidão, o genocídio, as divisões religiosas, a rebelião e a revolução. Estes assuntos ecoam no mundo contemporâneo e estão ligados a problemas que ainda nos desafiam (tais como os direitos humanos e as liberdades), e sobre os quais todo cidadão deve ter uma posição considerada e informada (BARTON, 2004). Criar o entendimento histórico nos seus estudantes pela construção de sua capacidade para o pensamento histórico é certamente o objetivo de qualquer professor de história. Contudo, esta ambiciosa missão pedagógica pode tornar-se vaga nas prescrições e nos requerimentos 
Contudo, diferentemente do desenvolvimento profissional que ocorreu em relação à geração de professores dos anos 1980, parece haver pouco apoio governamental para professores em serviço no novo currículo nacional, e o desenvolvimento profissional parece ter sido deixado às associações de professores profissionais. Embora isto possa não ser um problema para NSW, poderia trazer dificuldades para estados nos quais o currículo de estudos sociais gerais são a prática padrão que se mantém. Certamente, nesses estados, é mais provável que professores experimentem antes de entrar no mercado de trabalho um curso de método de estudos sociais genéricos que reduz a história ao "aprendizado de investigação" e a um leve senso de "continuidade e mudança", nem sempre havendo no currículo espaço para visitar algumas das mais sutis dimensões do pensamento histórico que se verifica quando a história é ensinada com um método discreto.

Neste artigo, também investigamos o curso adicional de história de NSW, um experimento curricular exitoso que introduz os alunos veteranos de história em um estudo detalhado da natureza da história e no conjunto de tradições historiográficas que entram na sua construção. Defendemos que o curso de história adicional oferece a reconceitualização de uma visão das habilidades do pensamento histórico, indo além do “olhar disciplinar”, chegando ao reino do entendimento meta-histórico. Quando confrontado com narrativas históricas concorrentes, o aluno do curso adicional de história pode trazer o seu entendimento da historiografia para fornecer quadros judiciosos de referência através dos quais se possa ler relatos históricos alternativos, expondo vieses metodológicos e pressuposições inerentes que dão suporte às interpretações rivais do passado que eles encontram. Quando o pensamento histórico opera neste nível meta-disciplinar, surge a consciência crítica que acompanha o seu possuidor ao navegar as águas complexas da vida sociocultural. Contudo, adotar uma abordagem historiográfica do ensino de história, tal como aquela que foi criada no curso adicional de história de NSW significa que é necessário aos educadores de história, e certamente aos formadores de professores, abordar a historiografia no ensino e na 
formação de professores de história. O conhecimento da historiografia e o seu impacto na metodologia e nas formas de representação se tornam centrais para o esforço de representar a história nas salas de aula. Separado da historiografia, qualquer encontro com práticas disciplinares de história, o modo usual pelo qual representamos o pensamento histórico, tende a esconder a controvérsia que é central para a investigação e a representação histórica.

\section{Referências}

AHONEN, Sirkka. Coming to terms with a dark past: how post-conflict societies deal with history. New York: Peter Lang, 2012.

AL-HAJ, Majid National ethos, multicultural education, and the new history textbooks in Israel. Curriculum Inquiry, v. 35, n. 1, p. 47-71, 2005.

ALDRICH, Richard. History in the national curriculum. London: Kogan Page, 1991.

APPLE, Michael W. The hidden curriculum and the nature of conflict. In: PINAR, William (Org.). Curriculum theorizing: the reconceptualists. Berkley, C.A. McCutchan Publishing Corporation, 1975. p. 95-119.

BARCAN, Alan. A history of Australian education. Melbourne: Oxford University Press, 1980.

BARTON, Keith C. Teaching history for the common good. Chicago: Lawrence Erlbaum, 2004.

BENNETT, Tony. The birth of the museum: history, theory, politics. London: Routledge, 1995.

BLAINEY, Geoffrey. Drawing up a balance sheet of our history. Quadrant, v. 37, n. 7-8, p. 10-15, 1993.

BOARD OF STUDIES NSW. History stages 4-5 syllabus. Sydney, NSW: 1998.

BOARD OF STUDIES NSW. HSC history extension syllabus. Sydney, NSW: 2000.

BOARD OF STUDIES NSW. History years 7-10 syllabus (mandatory and elective courses). Sydney, NSW: 2003. 
CLARK, Anna. Teaching the nation: politics and pedagogy in Australian history. Melbourne, VIC: Melbourne University Press, 2004.

CLARK, Anna. What do they teach our children? In: MACINTYRE, S.; CLARK, A. (Org.). The history wars. Melbourne: Melbourne University Press, 2003. p. 171-190.

CLARK, Anna. History's children: history wars in the classroom. Sydney: University of New South Wales Press, 2008.

COUNSELL, Christine. Historical knowledge and historical skills: A distracting dichotomy. In: ARTHUR, James; PHILLIPS, Robert (Org.). Issues in History teaching. London: Routledge, 2000. p. 52-71.

CROWE, David. Christopher Pyne tackles leftist 'bias' in classrooms. The Australian. Canberra: News Corp Australia. Midday 2014.

DONNELLY, Kevin. The black armband view of history. Agora, v. 32, n. 2, p. 15, 1997.

FITZGERALD, Janis. History and the core curriculum: a response to core curriculum for Australian schools. Teaching History, v. 15, n. 2, p. 69-85, 1981.

GADAMER, Hans-Georg. Truth and method. New York: Crossroad, 1992.

GRIMSHAW, Pat. History: Searching for identity. Annual State Conference of the Queensland History Teachers Association (QHTA), 1996, Brisbane.

GUYVER, Robert. The shape of the Australian history curriculum: a comparative perspective. Agora, v. 44, n. 4, p. 9-16, 2009.

HALSE, Christine; HARRIS, Catherine. National identity and social cohesion: the social use of history curriculum in the United Kingdom, the US and Australia. Annual Conference of the Australian Association for Research in Education (AARE), 2004, University of Melbourne, November 28 - December 2, 2004.

HARRIS, Catherine. History curriculum development in New South Wales: issues of control and its impact on teachers. Annual Conference of the Australian Association for Research in Education (AARE), 2004, University of Melbourne, VIC.

HENDERSON, Deborah J. What is education for? Situating history, cultural understandings and studies of society and environment against neo-conservative critiques of curriculum reform. Australian Journal of Education, v. 49, n. 3, p. 306-319, 2005.

HOWARD, John. Unity vital in battle against terrorism. The Sydney Morning Herald. Sydney: 11 p. 2006. 
HUGHES-WARRINGTON, Marnie et al. Historical thinking in higher education: An ALTC discipline-based initiative. Australian Learning and Teaching Council. Sydney. 2009

JOHNSTON, Gary. An historical perspective of the 1980 syllabus in history for years 7-10. Teaching History, v. 15, n. 4, p. 65-81, 1982.

LAND, Ray. Invasion and after: a case study in curriculum politics. Brisbane: Queensland Studies Centre, 1994.

LEE, Paul. Historical literacy: Theory and Research. International Journal of Historical Learning, Teaching and Research, v. 5, n. 1, 2005.

LEE, Paul; ASHBY, Rosalyn. Progression in historical understanding ages 7-14. In: STEARNS, Peter N.; SEIXAS, Peter; WINEBURG, Samuel(Org.). Knowing, teaching, and learning history: national and international perspectives. New York: New York University Press, 2000. p. 199-222.

LEINHARDT, Gaea; BECK, IsabelL.; STAINTON, Catherine. Teaching and learning in history. Hillsdale, NJ: Lawrence Erlbaum Associates, 1994.

MACINTYRE, Stuart. The history wars. Teaching History, v. 38, n. 2, p. 4-14, 2004.

MACINTYRE, Stuart; CLARK, Anna. The history wars. Melbourne: Melbourne University Press, 2003.

MACRAILD, Donald M.; TAYLOR, Avram. Social theory and social history. London: Palgrave Macmillan, 2004.

MELLEUISH, Gregory. The teaching of Australian history in Australian schools: a normative approach. The Australian History Summit, 2006, Canberra. August 17.

NASH, Gary B.; CRABTREE, Charlotte; DUNN, Ross E. History on trial: culture wars and the teaching of the past. New York: Alfred A, Knopf, 1998.

OSBORNE, Graeme; MANDLE, WilliamFrederick (Orgs.). New history: studying Australia today. Sydney: George Allen \&Unwined. 1982.

PARKES, Robert John. Reading History curriculum as postcolonial text: towards a curricular response to the history wars in Australia and beyond. Curriculum Inquiry, v. 37, n. 4, p. 383-400, 2007.

PARKES, Robert John. Teaching History as historiography: engaging narrative diversity in the curriculum. International Journal of Historical Learning, Teaching and Research, v. 8, n. 2, p. 118-132, 2009. 
PARKES, Robert John. Interrupting history:rRethinking history curriculum after 'the end of history'. New York: Peter Lang, 2011.

PHILLIPS, Robert. History teaching, nationhood and the state: a study in educational politics. London: Cassell, 1998.

RICHARDSON, George H. The death of the good Canadian: teachers, national identities, and the social studies curriculum. New York: Peter Lang, 2002.

SECONDARY SCHOOLS BOARD. History Syllabus: secondary Schools. Sydney, NSW: Secondary Schools Board 1971.

SECONDARY SCHOOLS BOARD. History in N.S.W. secondary Schools, Years 7-10. Sydney, NSW: Secondary Schools Board, 1980.

SEGALL, Avner. What's the purpose of teaching a discipline, anyway? In: SEGALL, Avner; HEILMAN, Elizabeth; CHERRYHOLMES, Cleo H (Org.). Social studies - the next generation: re-searching in the postmodern. New York: Peter Lang, 2006. p. 125-139.

SEIXAS, Peter. Historical understanding among adolescents in a multicultural setting. Curriculum Inquiry, v. 23, n. 3, p. 301-327, 1993 a.

SEIXAS, Peter. Popular film and young people's understanding of the history of Native American-White relations. The History Teacher, v. 26, n. 3, p. 351-370, $1993 \mathrm{~b}$.

SEIXAS, Peter. Benchmarks of Historical Thinking: a framework for assessment in Canada. Centre for the study of historical consciousness, University of British Columbia.

Vancouver, CA. 2006

SHARPE, Jim. History from below. In: BURKE, Peter(Org.). New perspectives on historical writing. Cambridge, UK: Polity Press, 1991. p. 24-41.

SHEMILT, Denis. History 13-16: evaluation study. Edinburgh: Holmes McDougall, 1980.

TAYLOR, Tony. Howard's End: a narrative memoir of political contrivance, neoconservative ideology and the Australian history curriculum. Curriculum Journal, v. 20, n. 4, p. 317-329, 2009. ISSN 0958-5176.

TAYLOR, Tony; CLARK, Anna. An overview of the teaching and learning of Australian history in schools. The Australian History Summit, Canberra. Canberra 2006.

TAYLOR, Tony; GUYVER, Robert(Orgs.). History wars in the classroom: Global perspectives. London: Information Age Publishinged. 2011. 
TAYLOR, T.; YOUNG, C. Making history: A guide for the teaching and learning of history in Australian schools. Carlton South, VIC: Curriculum Corporation, 2003.

THOMPSON, K. Civics and citizenship education in New South Wales and its implications for teaching history. 1999. thesis submitted in partial fullfilment of the requirements for the degree of Bachelor of Education (Honours) Faculty of Education, The University of Sydney

VAN BOXTEL, C; VAN DRIE, J. Historical reasoning: a comparison of how experts and novices contextualise historical sources. International Journal of Historical Learning, Teaching and Research, v. 4, n. 2, 2004.

VANSLEDRIGHT, B. A. Closing the gap between school and disciplinary history? Historian as high school history teacher. In: BROPHY, J (Org.). Advances in Research on Teaching. Greenwich, Conn.: JAI Press, v.6, 1996. p. 257-289.

VIRTA, A. Historical literacy: Thinking, reading and understanding history. Journal of Research in Teacher Education, v. 14, n. 4, p. 11-25, 2007.

WILSON, S. M.; WINEBURG, S. Peering at history through different lenses: the role of disciplinary perspectives in teaching history. Teachers College Record, v. 89, n. 4, p. 525539, 1998.

WINDSCHUTTLE, K. The killing of history: How literary critics and social theorists are murdering our past. New York: The Free Press, 1996.

WINEBURG, S. Historical thinking and other unnatural acts. Canadian Historical Consciousness in an International Context: theoretical Frameworks conference, 2001, University of British Columbia, Vancouver, BC.

WINEBURG, S. Historical thinking and other unnatural acts: charting the future of teaching the past. Philadelphia: Temple University Press, 2001.

YILMAZ, K. Introducing the 'linguistic turn' to history education. International Education Journal, v. 8, n. 1, p. 270-278, 2007. 
Recebido em: 10/01/2014 Aprovado em: 10/03/2014

Universidade do Estado de Santa Catarina - UDESC Programa de Pós-Graduação em História - PPGH Revista Tempo e Argumento Volume 06 - Número 11 - Ano 2014 tempoeargumento@gmail.com 